\title{
Editor's Introduction: Disciplinary and Departmental Boundaries, and Possible Crossings
}

\author{
Lawrence T. Nichols ${ }^{1}$
}

Published online: 20 February 2018

(C) Springer Science+Business Media, LLC, part of Springer Nature 2018

We begin with an interview of Randall Collins by Jerome Ferret, which is translated from the original French and reprinted here with permission. This wide ranging exchange conveys a sense of sociology as a living tradition and an ongoing intellectual challenge. Along the way, it also provides a brief intellectual biography of Collins, from his early work on social conflict that was rooted in the turmoil of the 1960s and the reaction against the functionalist paradigm, to his subsequent "interactionist turn," and thence to his most recent work on violence and policing. My colleagues and I had the privilege, and the pleasure of hearing Professor Collins lecture at West Virginia University a couple of years ago, and we were all impressed by his relentless drive to comprehend the social world ever more fully. I also felt strongly that his insightful research on situations of interpersonal violence revealed how poorly the field of sociology has actually understood these dynamics, especially the distorted "tunnels" of perception that actors enter, which are also absent from most mass media depictions. In short, we find here a great example of "sociology as a vocation."

The three following articles deal in one way or another with economics and with the relationship, still in flux, between that discipline and sociology. The first, by Steven Foy, Cyrus Schleifer and Edward Tiryakian, seeks to explain how Rational Choice Theory, a perspective long rejected in sociology, rose to both theoretical and institutional prominence in the field during the 1980s and 1990s. These authors focus on a set of factors, both within sociology itself and in its larger sociocultural setting, that they believe account for the success of the RCT approach, even in the face of deeply entrenched opposition. This analysis, which seeks to combine social structural and cultural logics of explanation, accords well with a longstanding emphasis in this journal on intellectual movements in the field, including their periods of florescence and decline.

Lawrence T. Nichols

lnichol2@wvu.edu

1 West Virginia University, Morgantown, WV, USA 
The second socioeconomic article comes to us from Professor Milan Zafirovski, who has been a frequent contributor to this journal. This analysis seeks to upend many conventional views by arguing that economics has not been exclusively a study of rational choice, but has also, since its modern formative period, also considered the phenomenon of apparently irrational choices. Economics, in other words, has actually been a dual or multiple paradigm field. This has been its "best kept secret," one which, like Edgar Allen Poe's famous "purloined letter," has been hiding in plain sight.

The third and final article in the set, by Dustin Stoltz, makes a fresh effort to bridge the persisting gap between the fields of economics and sociology, a gap many have found puzzling given the historical fact of many early sociology departments emerging from university departments of political economy or economics. Stoltz traces the recent attempt by advocates of formal network theory to create an interdisciplinary link, and discusses why this has not proven successful. The analysis then introduces an emergent paradigm that might rise to the challenge, known as "relational economic sociology," an approach that the author hopes will stimulate constructive and sustained dialogue.

The next two articles address the ongoing debate over the nature of science itself, the status of sociology among the social disciplines, and significant shifts in the larger context of scientific work. Paolo Parra Saiani begins by expressing concern about yet another attempt to reduce science to one particular type of scientific work, in this case, experimentation and, more specifically, that based on "randomized controlled trials" (RCT). However, in contrast to many well known efforts within sociology itself to reduce the field to "social physics" or some other imitative version of natural science, the key players are located outside the academy, in the realm of politics and law. A particular danger arises in connection with external funding of social science research, when those in the public sphere who control research budgets impose a mandate of, in effect, "RCT only." This emerging, politicized "gold standard" hearkens back to an issue that I have examined in my own published research on the history of our field, namely, "scientific vulnerability." As Pitirim Sorokin liked to say, all ongoing systems have some "margin of autonomy," but this always has limits. In the case of sociology, and of social science more generally, autonomy has been limited both by the increasing need for external funding and by the difficulties of maintaining legitimacy in the eyes of those who control the purses (whether public or private) and who are not well versed in matters of epistemology.

The following article, by Anson $\mathrm{Au}$, addresses the challenging issue of the relations between choice of research method and knowledge production in science. The author presents a sophisticated, hierarchical clustering model of textual representations (i.e., titles and abstracts) of journal articles over the course of some sixty years, from the mid-twentieth century to the first decade of the new millennium. Au argues that two key epistemological moves are crucial, namely, how researchers divide the social world into some form of analyzable data, and how they frame data and thus recursively influence future knowledge production. The article concludes that, despite what sometimes seem to be "panics" over the incipient hegemony of certain, especially quantitative methods (e.g., "Big Data"), sociologists in both qualitative and quantitative camps have actually been inventing a new approach, an empiricism that both mediates and is mediated by, knowledge production, via discursive and theoretical compartmentalization. In order to clarify their own largely unrecognized inventiveness, however, sociologists need to raise awareness of its philosophical and historical underpinnings. 
Jessica Cohen's commentary on Anthony J. Blasi's book Sociology of Religion in America: A History of a Secular Fascination with Religion, was originally intended to be part of a larger set of papers, a sort of mini-symposium on Blasi. Due to a variety of real-life complications, the prospective set did not emerge as planned, and so we offer the paper here separately. Professor Cohen praises Blasi's history as a valuable resource for both educators and students, especially in terms of three crucial issues: the problem of objective knowledge of faith-based phenomena; the best approach to the sociological study of religion today; and a comparison of today's subfield to that of a century ago.

If I might offer a constructive suggestion, as a sociologist long interested in religion though not expert in the field, and as a person with a lifelong involvement in organized religion, it would be that we broaden our framing of the field to that of "spirituality and religion." Many readers are doubtless aware that a growing number of persons describe themselves as "spiritual, but not religious," and I think that we ought to regard that, in itself, as a significant phenomenon and a trend for sociological analysis. Our contemporary context also includes significant movements in the direction of "inter-spirituality," as exemplified by the writings of the late Brother Wayne Teasdale (e.g., The Mystic Heart, and A Monk in the World), especially a collection he co-edited with Martha Howard, entitled Awakening the Spirit, Inspiring the Soul: 30 Stories of Interspiritual Discovery in the Community of Faiths. The popular and influential writings of independent scholar Karen Armstrong (best known for A History of God) offer further support for this "sociology of spirituality and religion" approach, which I offer not as an evangelist but as a sociologist interested in a significant, emergent and thus far neglected phenomenon. Readers of this journal may also recall, in this connection, Janine Schipper's 2012 article, "Toward a Buddhist Sociology: Theories, Methods, and Possibilities."

Our issue concludes with an article by Nathan Palmer, Ted Brimeyer and April Schueths on a topic in which I have been greatly interested for many years, namely, forming collegial relationships in academic departments. These authors examine the situation of the increasing number of contingent faculty in our colleges and universities, and raise the issue of the degree of their integration into the social networks of departments. In particular, they examine data on the extent to which access to Open Educational Resources (OERs) might facilitate the creation of collegial relationships at the departmental level. Perhaps their study will elicit further research on such possibilities.

Those conversant with the history of sociology in Europe and America over the past two centuries are well aware that a key issue for many of the most influential figures was the increasingly depersonalized character of contemporary social life. The problem was variously framed - in what might be regarded as the classical period-as "alienation" (Marx), or "the stranger" (Simmel), or "anomie" (Durkheim) or "rationalization" (Weber), as well as "gesellschaft" (Toennies), and loss of "the neighborly relation" (Jane Addams). Later generations would continue to examine the issue in terms of "the eclipse of community" (Maurice Stein) or "white collar" occupations (C. Wright Mills), along with "the lonely crowd" (Riesman, Glazer, Denney) and "the pursuit of loneliness" (Philip Slater). The issue resonates with DuBois's poignant early analysis of "the veil," and Christian Smith's more recent query, "What is a person?" Given this sustained concern, it is ironic how often sociology departments themselves exemplify depersonalization, as I can myself attest on the basis of experience teaching in ten 
different units, at several "levels" of the academic pyramid (community college, state college, large public research university, private university), in several states. Sociologists routinely urge their students to care more about others, especially disadvantaged, oppressed or marginalized groups, and yet one often has to wonder whether they even care about their own colleagues. How, we might ask, can we create a more caring world if we cannot even create a more caring department? Can we somehow get beyond a distant, detached, self-absorbed "professionalism," oriented always toward scoreboards and stardom, and treat our colleagues, as well as our students, with loving kindness? 